\title{
HUBUNGAN VISUS DENGAN RISIKO JATUH PADA LANSIA KELURAHAN BACIRO KOTA YOGYAKARTA
}

Diterima: 27-02-2018 D Disetujui: 18-10-2018

http://dx.doi.org/10.21460/bikdw.v3i2.100

\section{Amadea Rigenastiti, The Maria Meiwati Widagdo, Yanti Ivana Suryanto} Fakultas Kedokteran Universitas Kristen Duta Wacana

Korespondensi: amadearigenastiti@gmail.com

\begin{abstract}
ABSTRAK
Latar Belakang: Proses penuaan menyebabkan terjadinya perubahan fungsi fisiologis dan psikososial seseorang. Jumlah lansia pada tahun 2015 di provinsi DI Yogyakarta menempati urutan pertama di Indonesia dengan persentase $13,49 \%$. Semakin banyak jumlah lansia, maka permasalahan yang akan timbul pada lansia juga semakin banyak. Salah satu permasalahan yang sering terjadi pada lansia adalah jatuh. Risiko jatuh terdiri dari faktor intrinsik dan faktor ekstrinsik. Visus (ketajaman mata) merupakan bagian dari faktor intrinsik risiko jatuh pada lansia.

Tujuan: Mengukur ada atau tidaknya hubungan visus dengan risiko jatuh pada lansia di Kelurahan Baciro Yogyakarta

Metode Penelitian: Metode yang digunakan dalam penelitian ini adalah observasional-analitik dengan desain cross sectional. Peneliti mengambil sampel di Kelurahan Baciro Yogyakarta. Kriteria inklusi pada sampel penelitian ini adalah lansia berusia $\geq 60$ tahun. Kriteria eksklusinya yaitulansia denganbuta huruf dan mempunyai keterbatasan neuromotorik di ektremitas bawahnya. Pengambilan data dilakukan dengan memeriksa visus lansia dengan kartu Snellen lalu memeriksa risiko jatuhnya dengan menggunakan kuesioner Falls Efficacy Scale International (FES-I).

Hasil Penelitian: Terdapat 97 lansia yang menjadi responden dengan hasil analisis bivariat dengan uji korelasi Spearman menunjukkan tidak terdapat hubungan antara visus mata terbaik dengan risiko jatuh pada lansia (FES-I) $(\mathrm{p}=0,063$ dan $\mathrm{r}=0,190)$, namun pada kelompok visus mata terburuk didapatkan hasil bahwa terdapat hubungan antara visus mata terburuk dengan risiko jatuh pada lansia ( $\mathrm{p}=0,018$ dan $\mathrm{r}=0,240)$.

Kesimpulan: (1) Tidak terdapat hubungan antara visus mata terbaik dengan risiko jatuh pada lansia. (2) Terdapat hubungan antara visus mata terburuk dengan risiko jatuh pada lansia.
\end{abstract}

Kata Kunci: visus, risiko jatuh, FES-I 


\title{
THE CORRELATION OF VISUAL ACUITY AND THE RISK OF FALLS OF OLDER PEOPLE AT BACIRO VILLAGE YOGYAKARTA
}

\author{
Received: 27-02-2018 - Accepted: 18-10-2018
}

http://dx.doi.org/10.21460/bikdw.v3i2.100

\author{
Amadea Rigenastiti, The Maria Meiwati Widagdo, Yanti Ivana Suryanto \\ Medical Faculty of Duta Wacana Christian University \\ Correspondence: amadearigenastiti@gmail.com
}

\begin{abstract}
Background: The aging process causes changes of physiological and psychosocial functions. The percentage of older people population in Yogyakarta Province in 2015 was 13,49\%, the highest in Indonesia. The increased number of older people is followed by the increased number of problems in older people. One of the most common problems of older people is falls. Risk of falls consists of intrinsic and extrinsic factors. Visual acuity is a part of the intrinsic factor of risk of falls in the older people.

Objective: To find out the correlation between visual acuity and the risk of falls of older people in Baciro Village Yogyakarta

Methods: The research method was observational-analytic with cross sectional design. Researchers took samples in Baciro Village Yogyakarta. The inclusion criteria was people aged $\geq 60$ years old. The exclusion criteria were older people who were illiterate and had neuromotor limitations in lower extremity. The data was collected by checking the visual acuity of the older people with Snellen chart. Falls Efficacy Scale International (FES-I) questionnaire was used to determine the risk of falling.

Results: Ninety-seven older people participated in this research. The results of bivariate analysis used Spearman correlation test showed that there was no correlation between the better eye visual acuity and the risk of falls in the older people (FES-I) ( $r=0.190$ and $p=0.063)$ and there was a significant correlation between the worse eye visual acuity and the risk of falls in the older people ( $r=0.240$ and $p=0.018$ ).

Conclution: (1) There is no correlation between the better eye visual acuity and the risk of falls in the older people. (2) There is a correlation between the worse eye visual acuity and the risk of falls in the older people.
\end{abstract}

Keywords: visual acuity, risk of falls, FES-I 


\section{PENDAHULUAN}

Proses penuaan menyebabkan terjadinya perubahan fungsi fisiologis dan psikososial seseorang. ${ }^{1}$ Jumlah lansia pada tahun 2015 di provinsi DI Yogyakarta menempati urutan pertama di Indonesia dengan persentase $13,49 \% .^{2}$ Semakin banyak jumlah lansia, maka permasalahan yang akan timbul pada lansia juga semakin banyak. Salah satu permasalahan pada lansia yang sering terjadi adalah jatuh. Pada tahun 2014, CDC melaporkan bahwa di Amerika Serikat terdapat sekitar $30 \%$ lansia yang berumur lebih dari 65 tahun jatuh setiap tahunnya. ${ }^{3}$

Perubahan penglihatan merupakan bagian dari penyesuaian dalam kehidupan usia lanjut. Dalam penuaan, kondisi gangguan penglihatan yang dianggap normal berupa penurunan akomodasi mata, penurunan ukuran pupil, serta perubahan warna dan keruhnya lensa mata. ${ }^{4}$ Berbagai perubahan penglihatan yang terjadi pada lansia dapat menyebabkan penurunan visus. Berikut ini adalah penggolongan gangguan penglihatan menurut tajam penglihatan dan penglihatan kurang (low vision): (1) penglihatan normal $(6 / 3-6 / 7,5)$, (2) penglihatan hampir normal (6/9$6 / 21)$, (3) low vision sedang $(6 / 24-$ $6 / 38)$, (4) low vision berat $(6 / 60-$ $6 / 240)$, (5) low vision nyata6 (6/240), (6) hampir buta (penglihatan <4 kaki untuk menghitung jari) dan (7) buta total (tidak mampu mengenal sinar). ${ }^{5}$ Pemeriksaan mata dengan kartu Snellen merupakan standar pemeriksaan untuk mengetahui ketajaman penglihatan seseorang desimal. ${ }^{6}$ Orang yang memiliki visus yang buruk dapat meningkatkan risiko jatuh sebanyak dua kali lipat. ${ }^{7}$ Risiko jatuh pada lansia terdiri dari faktor intrinsik dan ekstrinsik. ${ }^{8}$ Penurunan visus merupakan bagian dari faktor intrinsik risiko jatuh pada lansia. ${ }^{8}$

Jatuh dapat mengakibatkan trauma serius, kelumpuhan, rasa nyeri, hingga kematian. ${ }^{9} \mathrm{Hal}$ tersebut juga dapat menimbulkan rasa takut dan hilangnya kepercayaan diri pada lansia, sehingga lansia lebih memilih untuk membatasi aktivitas sehariharinya. ${ }^{9} \mathrm{FES}-\mathrm{I}$ merupakan kuesioner yang digunakan untuk mengukur tingkat keberanian/ tingkat kepercayaan diri lansia terhadap aktivitasnya dan dikaitkan dengan risiko jatuh. ${ }^{10}$ Kuesioner FES-I yang digunakan mempunyai 25 pertanyaan dan 4 skala nilai (nilai $1=$ tidak berani, $2=$ sedikit berani, 3=cukup berani, dan 4=sangat berani). ${ }^{11}$ Penelitian Achmanagara (2012) membagi nilai FES-I kedalam 2 kelompok yaitu takut jatuh (nilai s84) dan tidak takut jatuh (nilai >84). ${ }^{11}$ Semakin rendah nilai FES-I yang didapatkan, maka semakin tinggi rasa takut jatuh seorang lansia, begitu pula sebaliknya. ${ }^{11}$ Takut jatuh merupakan faktor psikologis penting yang terkait dengan kejadian jatuh pada orang tua. ${ }^{10}$

\section{METODE PENELITIAN}

Penelitian dilakukan menggunakan metode observasionalanalitik dengan desain cross sectional. Kriteria inklusi sampel dalam penelitian ini yaitu orang yang berusia $\geq 60$ tahun, sedangkan kriteria eksklusinya yaitu lansia dengan buta huruf dan lansia yang mempunyai keterbatasan neuromotorik di ektremitas bawahnya. Penelitian ini dilakukan di Kelurahan Baciro, Yogyakarta. Pengambilan data dilakukan dengan cara memeriksa visus mata kanan dan kiri lansia dengan kartu Snellen (bagi lansia yang kesehariannya menggunakan kacamata, visusnya tetap diukur dengan menggunakan kacamata). Risiko jatuh diukur 
dengan menggunakan kuesioner Falls Efficacy Scale International (FES-I). Kuesioner FES-I yang digunakan peneliti mempunyai 25 pertanyaan dan 4 skala nilai (nilai $1=$ tidak berani, $2=$ sedikit berani, 3=cukup berani, dan 4=sangat berani). Semakin rendah nilai FES-I maka lansia memiliki rasa takut jatuh yang semakin tinggi atau dapat dikatakan risiko jatuhnya semakin tinggi, begitu pula sebaliknya. Penelitian ini dilaksanakan setelah peneliti mendapatkan surat pernyataan kelaikan etik (ethical clearance) dari Komite Etik Penelitian Kesehatan Nomor: 523/C.16/FK /2017 Fakultas Kedokteran
Universitas Kristen Duta Wacana Yogyakarta.

\section{HASIL PENELITIAN}

Jumlah sampel yang terkumpul sebanyak 97 orang. Terdapat 33 lansia laki-laki dan 64 lansia perempuan. Rentang usia responden dalam penelitian ini adalah 60 hingga 92 tahun.

Hasil visus yang didapatkan dibagi menjadi 7 kelompok yaitu: buta total, hampir buta, low vision nyata, low vision berat, low vision sedang, penglihatan hampir normal, dan penglihatan normal. Frekuensi dan persentase kelompok visus dapat dilihat pada tabel 1 .

Tabel 1. Frekuensi dan persentase kelompok visus

\begin{tabular}{lcccc}
\hline \multirow{2}{*}{ Visus } & \multicolumn{2}{c}{ OD } & \multicolumn{2}{c}{ OS } \\
\cline { 2 - 5 } & Frekuensi & Persentase & Frekuensi & Persentase \\
\hline Buta total & 3 & $3,1 \%$ & 4 & $4,1 \%$ \\
Hampir buta & 2 & $2,1 \%$ & 1 & $1,0 \%$ \\
Low vision nyata & 3 & $3,1 \%$ & 1 & $1,0 \%$ \\
Low vision berat & 7 & $7,2 \%$ & 9 & $9,3 \%$ \\
Low vision sedang & 25 & $25,8 \%$ & 20 & $20,6 \%$ \\
Penglihatan hampir normal & 49 & $50,2 \%$ & 53 & $54,6 \%$ \\
Penglihatan normal & 8 & $8,2 \%$ & 9 & $9,3 \%$ \\
Total & 97 & $100 \%$ & 97 & $100 \%$ \\
\hline
\end{tabular}

Masing-masing hasil visus dari mata kanan dan kiri dikelompokkan berdasarkan visus mata terbaik dan visus mata terburuknya. Keterangan mengenai kelompok visus mata terbaik dan mata terburuk dapat dilihat pada tabel 2 .

Tabel 2. Kelompok visus mata terbaik dan visus mata terburuk

Kelompok Visus

Buta total

Hampir buta

Low vision nyata

Low vision berat

Low vision sedang

Penglihatan hampir normal

Penglihatan normal

Total

Nilai FES-I dari seluruh sampel berkisar antara 47 hingga

3

2

5

19

57

11

97
Mata Terbaik

Mata Terburuk

\section{Frekuensi Persentase Frekuensi Persentase}

$3,1 \%$

$2,1 \%$

4

$4,1 \%$

$1,0 \%$

$4,1 \%$

$5,2 \%$

$19,6 \%$

$58,8 \%$

$11,3 \%$

$100 \%$

$11,3 \%$

$26,8 \%$

$46,4 \%$

$6,2 \%$ $100,0 \%$ 100. Rata-rata nilai FES-I sebesar 88,79. Distribusi nilai FES dapat 
dinilai pada gambar 1. Hasil FES-I dari lansia yang mempunyai gangguan penglihatan berat (hampir buta dan buta total) pada kedua mata ditampilkan pada tabel 3. Hasil FESI dikelompokkan menjadi 2 kelompok yaitu takut jatuh dan tidak takut jatuh yang dapat dilihat pada tabel 4.

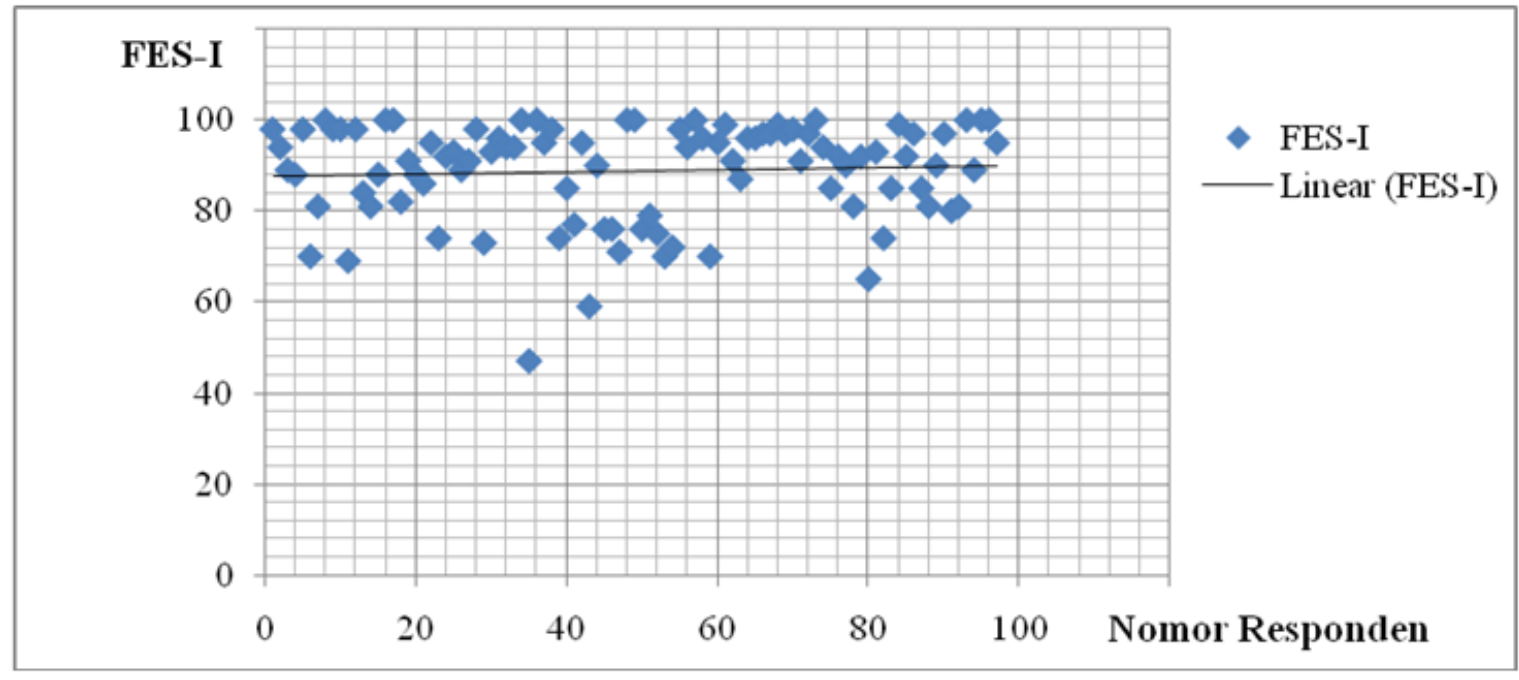

Gambar 1. Distribusi Nilai FES-I

Tabel 3. FES-I pada gangguan penglihatan berat

\begin{tabular}{lcc}
\hline \multicolumn{1}{c}{ Gangguan Penglihatan } & FES-I & $\begin{array}{c}\text { Rerata } \\
\text { FES-I }\end{array}$ \\
\hline Katarak berat (OD \& OS hampir buta) & 47 & \\
Katarak berat \& buta (OD: hampir buta \& OS: buta total) & 65 & \\
Glaukoma (OD \& OS buta total) & 59 & 68,5 \\
Buta sejak bayi (OD \& OS buta total) & 85 & \\
Buta sejak bayi (OD \& OS buta total) & 87 & \\
\hline
\end{tabular}

Tabel 4. Kelompok takut jatuh dan tidak takut jatuh (FES-I)

\begin{tabular}{lcc}
\hline \multicolumn{1}{c}{ Kelompok } & Frekuensi & Persentase \\
\hline Takut jatuh & 28 & $28,9 \%$ \\
Tidak takut jatuh & 72 & $74,2 \%$ \\
\hline
\end{tabular}

Visus pada kedua mata dipilih dan dikelompokkan berdasarkan visus terbaik dan visus terburuknya. Uji korelasi Spearman digunakan untuk mengetahui hubungan antara visus terbaik dan visus terburuk dengan risiko jatuh.

Hasil dari uji korelasi Spearman pada visus mata terbaik yaitu $r=0,190$ dan $p=0,063$. Nilai $\mathrm{p}>0,05$ pada kelompok visus mata terbaik menandakan bahwa tidak terdapat hubungan antara visus mata terbaik dengan risiko jatuh pada lansia (FES-I). Hasil analisis pada visus mata terburuk dengan risiko jatuh menunjukkan hasil nilai $\mathrm{r}=0,240$ dan $\mathrm{p}=0,018$. Nilai $\mathrm{p}<0,05$ pada kelompok visus mata terburuk dengan FES-I menandakan bahwa terdapat korelasi yang signifikan. Nilai $r$ positif menunjukkan hubungan positif searah antara visus mata terburuk dengan risiko jatuh pada lansia (FES-I). Semakin buruk visus pada lansia maka risiko jatuhnya semakin tinggi. 


\section{PEMBAHASAN}

Visus

Jumlah responden pada kelompok visus low vision nyata, hampir buta, dan buta total pada penelitian ini menempati urutan paling rendah. Rendahnya jumlah responden yang dikategorikan dalam kelompok-kelompok visus tersebut disebabkan karena kebanyakan lansia cenderung sudah pergi ke pusat layanan kesehatan untuk memeriksakan serta mengoreksi kondisi matanya. Kebutaan atau gangguan penglihatan lain sering dapat dikoreksi dengan strategi intervensi sederhana, berupa pemeriksaan mata secara rutin, menggunakan kacamata sesuai dengan anjuran dokter, serta melakukan operasi katarak. ${ }^{12}$

Dalam penelitian ini, terdapat beberapa orang yang mempunyai visus 0 (buta total) yang terdiri dari lansia yang buta sejak bayi dan lansia yang buta saat sudah dewasa. Dalam melakukan aktivitas seharihari, orang yang mengalami kebutaan sejak bayi memiliki kemampuan adaptasi lingkungan yang lebih baik daripada lansia yang buta saat dewasa. Walaupun perkembangan sensorik dan motorik pada penderita buta sejak bayi dapat mengalami hambatan, namun dalam masa perkembangan, pendengaran dan sensori lain akan semakin menonjol. ${ }^{13}$ Komponen visual dapat tergantikan sehingga anak dapat belajar untuk beradaptasi dengan lingkungannya lebih cepat. ${ }^{13}$

\section{FES-I}

Dalam penelitian ini, rata-rata hasil nilai FES-I yang didapatkan sebesar 88,79. FES-I dibagi dalam kelompok takut jatuh dan tidak takut jatuh, semakin tinggi FES-I maka semakin rendah risiko jatuhnya. Hasil populasi dari pengelompokkan lansia yang digolongkan menurut takut jatuh dan tidak takut jatuh yaitu sebanyak 28 orang (28,9\%) pada kelompok takut jatuh dan 72 orang $(74,2 \%)$ pada kelompoktidak takut jatuh Hasil FES-I yang tinggi dapat disebabkan karena risiko jatuh pada lansia dipengaruhi oleh berbagai faktor. Risiko jatuh tidak hanya dapat dipengaruhi oleh gangguan penglihatan, tetapi juga dapat dipengaruhi dengan keadaan fisik lansia atau kondisi lingkungan yang tidak aman. ${ }^{8}$

Peneliti mengambil sampel lansia yang masih memiliki kondisi fisik/ ekstremitas bawah yang baik yaitu lansia yang tidak menggunakan alat bantu jalan. Alat bantu jalan digunakan ketika seseorang mengalami penurunan kekuatan otot atau patah tulang pada anggota gerak bawah serta gangguan keseimbangan untuk berjalan. ${ }^{14}$ Kondisi tersebut dapat memperkecil risiko jatuh, sehingga hasil nilai FES-I yang didapatkan tidak banyak yang rendah. Terbukti dengan hasil persentase pengelompokkan lansia yang digolongkan menurut takut jatuh sebanyak $28,9 \%$ dan tidak takut jatuh $74,2 \%$.

\section{Hubungan Visus dengan Risiko Jatuh}

Hasil uji korelasi Spearman pada visus terbaik memiliki nilai $\mathrm{r}=0,190$ dan $\mathrm{p}=0,063$. Nilai $\mathrm{p}>0,05$ pada kelompok visus terbaik menandakan bahwa tidak terdapat hubungan antara visus terbaik dengan risiko jatuh pada lansia (FESI).

Hasil analisis pada visus terburuk menunjukkan hasil nilai $\mathrm{r}=0,240$ dan $\mathrm{p}=0,018$. Nilai $\mathrm{p}<0,05$ pada kelompok visus terburuk menandakan bahwa terdapat hubungan positif searah antara visus terburuk dengan risiko jatuh pada lansia (FES-I). Semakin buruk visus pada lansia maka risiko jatuhnya semakin tinggi. Semakin buruk gangguan penglihatan seseorang, 
maka semakin besar risiko jatuhnya. Orang yang memiliki visus yang buruk dapat meningkatkan risiko jatuh sebanyak dua kali lipat. ${ }^{7}$

Hasil penelitian ini didukung oleh penelitian yang dilakukan oleh Urata et al,. (2017) yang menyatakan bahwa lansia yang mempunyai visus lebih buruk memiliki rasa takut jatuh (FES-I) lebih tinggi. ${ }^{15}$ Urata et al. meneliti FES-I lansia pada 56 responden yang mengalami Age Related Macular Degeneration (ARMD), 64 responden yang mengalami glukoma sudut terbuka dan 52 responden sebagai kelompok kontrol. Hasil penelitian menunjukkan bahwa lansia dengan ARMD memiliki rerata visus yang paling buruk, skor yang didapatkan dari FES-I juga menunjukkan bahwa pasien merasa takut jatuh lebih tinggi daripada pasien lain. ${ }^{15}$

Penglihatan merupakan suatu komponen yang penting untuk menjaga keseimbangan tubuh. ${ }^{16} \mathrm{Hal}$ tersebut terbukti apabila seseorang berdiri dengan kedua mata yang ditutup, maka kemungkinan posisi tubuhnya akan bergoyang. ${ }^{16}$ Ketika mata tidak melihat maka ketidakstabilan postur tubuh akan meningkat sebesar 20-70\%. ${ }^{16}$

Orang yang mengalami gangguan visus berat di kedua belah matanya menunjukkan nilai FES-I dengan rata-rata 68,6 (tabel 3). Nilai FES-I dibawah 84 digolongkan dalam takut jatuh atau memiliki risiko jatuh.11 Seseorang yang memiliki gangguan penglihatan berat pada kedua matanya dapat meningkatkan risiko jatuh sebesar $60 \% .{ }^{17}$

Hasil korelasi Spearman visus mata terbaik dengan risiko jatuh pada lansia $(p=0,063)$ menandakan tidak terdapatnya hubungan antara visus mata terbaik dengan risiko jatuh pada lansia. Menurut CDC (2017) risiko jatuh dapat dipengaruhi faktor intrinsik dan faktor ekstrinsik. ${ }^{18}$ Faktor intrinsik risiko jatuh terdiri dari usia yang semakin tua, pengalaman jatuh sebelumnya, kelemahan otot, gaya berjalan dan gangguan keseimbangan, penglihatan yang buruk, hipotensi postural, riwayat penyakit kronis (arthritis, stroke, inkontinensia, diabetes, parkinson, demensia), serta takut jatuh. ${ }^{18}$ Faktor ekstrinsik dalam risiko jatuh pada lansia adalah kurang memadainya/ tidak terdapat pegangan anak tangga, desain tangga yang buruk, kurang memadainya/ tidak terdapat pegangan di kamar mandi, pencahayaan yang berlebih atau silau, rintangan dan bahaya tersandung, alas dengan permukaan licin atau tidak rata, konsumsi obat psikoaktif, dan penggunaan alat bantu jalan yang tidak benar. ${ }^{18}$

\section{KESIMPULAN}

Tidak terdapat hubungan antara visus terbaik dengan risiko jatuh pada lansia, namun terdapat hubungan antara visus terburuk dengan risiko jatuh pada lansia.

\section{DAFTAR PUSTAKA}

1. Mauk, K.L. 2010. Gerontological Nursing Competencies For Care (2nd ed). Sudbury: Janes and Barlett Publisher. (abstrak)

2. Badan Pusat Statistik. 2015. Statistik Penduduk Lansia. [Internet] November, 2016. Available at https://bps.go.id/ website/pdf_publikasi/StatistikPenduduk-Lanjut-Usia-2015-.pdf [Accessed September 5, 2017] Hal. 38, 60 (abstrak)

3. Ashar, PH. 2016. Gambaran Persepsi Faktor Risiko Jatuh Pada Lansia Di Panti Sosial Tresna Werdha Budi Mulia 4 Margaguna Jakarta Selatan. (Skripsi). Jakarta: UIN Syarif Hidayatullah. (abstrak)

4. Stanley, Mickey, and Patricia Gauntlett Beare. 2006. Buku Ajar Keperawatan Gerontik, ed 2. 
Jakarta: EGC Hal. 11-17, 128129

5. Ilyas S. 2008. Ilmu Penyakit Mata.Edisi Ketiga. Jakarta: Balai Penerbit FKUI. Hal. 64-71; 200226 (abstrak)

6. Hartono. 2011. Pemeriksaan Neurooftalmologi. Yogyakarta: Bagian Ilmu Penyakit Mata FK UGM. Hal. 5 (abstrak)

7. Harwood RH. 2001. Visual Problems and falls. [Internet] November, 2001. Available at https://www.ncbi.nlm.nih.gov/p ubmed/11769782

8. Darmojo, R. Boedhi, dan H. Hadi Martono. 2006. GERIATRI: Ilmu Kesehatan Usia Lanjut. Edisi ke3. Jakarta: Balai Penerbit FKUI. Hal. 58-66, 435-441

9. Stocklager, Jaime \& Schaeffer, Liz. 2008. Buku Saku Asuhan Keperawatan Geriatrik Edisi 2. Alih Bahasa: Nike Budhi Subekti. Jakarta: EGC. (abstrak)

10. Delbaere, et al. 2010. The Falls Efficacy Scale International (FESI). A comprhensive longitudinal validation study. Age Ageing, Volume 39, Issue 2. [Internet] Available at https://academic. oup.com/ageing/article-lookup/ doi/10.1093/ageing/afp225

[Accessed October, 18 2017] (abstrak)

11. Achmanagara, A. 2012. Hubungan Faktor Internal dan Eksternal dengan Keseimbangan Lansia di Desa Pamijen Sokaraja Banyumas. (Tesis). Jakarta: Universitas Indonesia. Hal. 48, 69-70. (abstrak)

12. Lord, Stephen R. 2006. Vision risk factors for falls in older people. [Internet] Available at https://academic.oup.com/ ageing/article/35/suppl_2/ii42/ 15788 [Accessed December 9, 2017]

13. Aulia, Fitri. 2014. Penyesuaian Diri Anak Luar Biasa (Studi Kasus Ade Irawan, Juara Pianis Tunanetra Indonesia). (Tesis). Yogyakarta: Universitas Islam Negeri (UIN) Sunan Kalijaga Yogyakarta. Hal. 71.

14. Kozier, Barbara (2009). Buku Ajar Praktik Keperawatan Klinis Kozier \& ERB, Ed. 5. Jakarta: EGC.

15. Urata et al,. 2017. The fear of fall in elderly subjects with eye diseases: a comparative analysis between glaucoma and agerelated macular degeneration patients from a developing country.[Internet] Available at https:/ /www.worldglaucoma.org /WGC/WGC2017/wgc2017_thefi les/uploads/ninja-forms /6/ P_WT_043.pdf_[Accessed January 29, 2018]

16. Brundle, Caroline, et al. 2015. The causes of fall: views of older people with visual impairment. [Internet] March, 2015. Available at https://www.ncbi.nlm. nih.gov/pmc/articles/PMC49495 46/ [Accessed August 31, 2017]

17. Lamoureux EL, et al. 2008. Visual impairment, causes of vision loss, and falls: the singapore malay eye study. [Internet] February, 2008. Available at http://iovs. arvojournals.org/article.aspx?art icleid $=2164456$

September 13, 2017]

18. CDC, 2017. Fact sheet: Risk Factors for Falls. [Internet]. Available at https:// www.cdc.gov/steadi/pdf/risk_fac tors_for_falls-a.pdf [Accessed January 30, 2018] 